\title{
Does child care availability play a role in maternal employment and children's development? Evidence from Italy
}

\author{
Ylenia Brilli \\ Daniela Del Boca \\ Chiara D. Pronzato
}

This version: September 19, 2013

\begin{abstract}
This paper investigates the effects of public child care availability in Italy in mothers' working status and children's scholastic achievements. We use a newly available dataset containing individual standardized test scores of pupils attending the second grade of primary school in 2009-10 in conjunction with data on public child care availability. Our estimates indicate a positive and significant effects of child care availability on both mothers' working status and children's Language test scores. We find that a percentage change in public child care coverage increases mothers' probability to work by 1.3 percentage points and children's Language test scores by 0.85 percent of one standard deviation; we do not find any effect on Math test scores. Moreover, the impact of a percentage change in public child care on mothers' employment and children's Language test scores is greater in provinces where child care availability is more limited.
\end{abstract}

Keywords child care $\cdot$ female employment child cognitive outcomes · test scores

JEL Classification J13 I2 H75

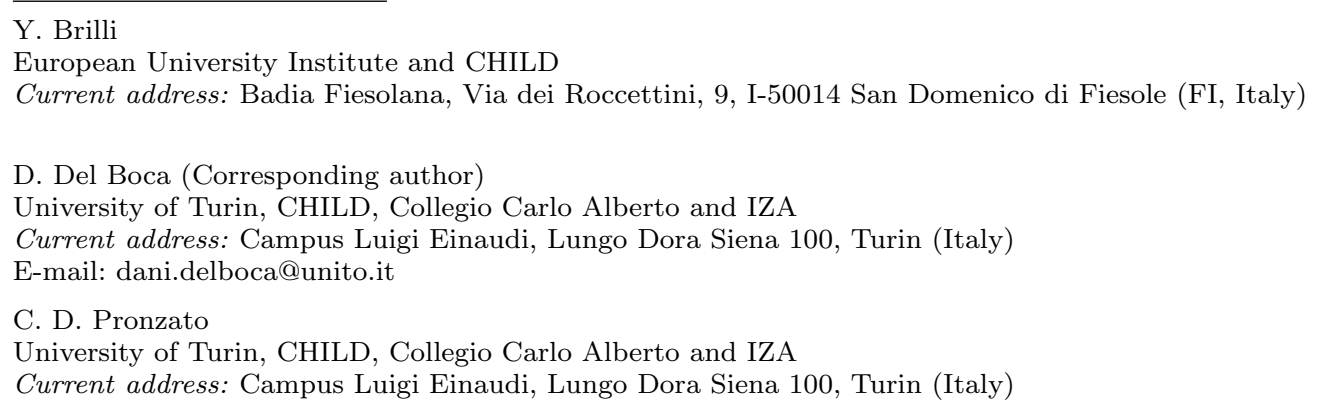




\section{Introduction}

Advocates for public intervention in child care provision offer two main arguments: (1) child care providing children's "physical care" may support mothers' participation in the labor market and (2) child care providing early childhood education may contribute to children's cognitive and non cognitive development, leading to gains in the accumulation of human capital in the society.

Existing research on the impact of child care supply on maternal employment has been recently accompanied by growing interest in the impact of child care on childhood development. Such studies suggest that children's cognitive and non cognitive outcomes are largely determined early in life and that returns on investments in early childhood are higher than those on investments at later stages, especially in the case of disadvantaged children (Carneiro and Heckman, 2003). Inputs from families as well as from the school system during early childhood play a very significant role in later cognitive, social, and behavioral outcomes (Heckman et al, 2006).

Child care institutions are important arenas for children's development, and expanding child care coverage is an explicit goal in many countries. In 2002, the European Union Presidency established the goal of providing "child care by 2010 to at least 90 percent of children between 3 years old and the mandatory school age and at least 33 percent of children under 3 years of age" (EU, 2002).

Exploring the roles of public child care is particularly important in Italy, since the labor market participation of mothers is much lower than in other European countries and children do less well in school than their European counterparts. In Italy, only 54 percent of mothers are employed, while this value is over 70 percent in the UK, France and Germany. ${ }^{1}$ Furthermore, according to 2006 data from PISA (the Programme for International Student Assessment), 15-year-old Italian students rank fourth from the bottom in average educational performance among advanced countries (OECD, 2007). Moreover, given the large number of children from single-child families, their main opportunities for early socialization may be those provided by child care services, and investments in child care policies may also help alleviate intergenerational persistence, especially for children from low income families. Instead, OECD data (OECD, 2010) show that public investment in pre-school education in Italy is among the lowest in Europe. ${ }^{2}$ In fact, according to ISTAT (2010), only 13 percent of children aged 0-2 years in Italy have access to public child care facilities and the demand for public child care is much higher than supply in all Italian regions. When child care applications outnumber supply, the municipalities, as the main decision makers in child care policies, allocate the limited number of slots using eligibility requirements. In some municipalities, eligibility criteria give priority to children from low income families, in order to provide better inputs for their development than those received at home and to reduce disparities. In other municipalities, priority is given to children with working mothers, in order to support them in combining parenthood and work.

Our paper explores the role of public child care in Italy, investigating its impact on mothers' working status and children's educational outcomes. We use a newly available dataset on children's primary school performance,

\footnotetext{
1 Data from Eurostat referred to 2009.

2 According to data from OECD Family Database for 2005, public expenditure on child care and early education services in Italy is equivalent to 0.6 percent of GDP, while this figure for France, Sweden and Denmark is higher than 1 percent (OECD, 2010).
} 
in conjunction with data on public child care coverage at the provincial level. Our identification strategy exploits cross-sectional variation in child care coverage across provinces to recover the effects of interests.

This paper contributes to the existing literature in two ways. First, differently from the majority of studies on this issue that deal with child care policies for children older than 3, we explicitly focus on early child care for children aged 0-2 years. A policy targeted toward very young children may have different effects on both outcomes, with respect to policies focused on children in preschool ages. Concerning mothers' employment, a policy offering external child care for children aged 0-2 may be more effective than a preschool policy in reducing the probability that mothers without alternative forms of care leave the labor market after childbirth. Concerning children's outcomes, instead, this study allows to test whether child care for the very young has an effect on cognitive outcomes measured at primary school. Recent literature, in fact, suggests that the returns of investments made during early years are higher than that of investments made later, and early learning increases the productivity of later learning (Carneiro and Heckman, 2003). Second, when considering the impacts of child care coverage on these outcomes, we take into account the potential non-linearity in child care impacts to see whether they change if the service is more rationed, i.e. less available.

In the base specification, controlling for children's and parents' characteristics as well as provinces' features, we find that child care availability is positively related to mothers' participation in the labor market and to Language test scores. We find that a percentage change in public child care coverage increases mothers' probability to work by 1.3 percentage points and children's Language test scores by 0.85 percent of one standard deviation of the scores distribution. We do not find any effect on Math test scores. These results are robust to the inclusion of province dummies and to several sensitivity checks. Once we allow for a non-linear effect, we find that in areas where the supply of child care is more limited the effect of a percentage change in child care supply on both mothers' employment and Language test scores is higher.

The rest of the paper is organized as follows. In Section 2 we review the existing literature concerning the impact of child care on both mothers' participation and children's cognitive outcomes. In Section 3 we describe public child care in Italy and its features, while in Section 4 we present a theoretical model, representing the framework for our empirical analysis. In Section 5 we define the empirical strategy and the issues involved in the estimation, while Section 6 provides a description of the data. Section 7 presents the results from the baseline estimation (subsection 7.1) and from the specification where non-linearity is taken into account (subsection 7.2); subsection 7.3 discusses the sensitivity checks that we perform. Finally, Section 8 concludes.

\section{The Literature}

In this section we review the most important studies related to the object of our present research: the relationship between public child care, mothers' labor supply and children's development. While the literature focusing on the 
link between child care and mothers' labor supply is quite large ${ }^{3}$ the studies on the link between public child care and children's development are more limited.

According to micro-economic theory, an increase in child care availability determines an increase in mothers' net wage, but the final impact on mothers' participation is unclear: in fact, an higher net wage may determine an increase in a mother's participation (substitution effect) or an increase in leisure time (income effect), which one prevails depends on the structure of a mother's preferences. Havnes and Mogstad (2011a) analyze the impact of a change in child care availability in Norway and find a very small effect on mothers' participation in the labor market, coherent with some studies for the U.S. (Cascio, 2009). Baker et al (2008) evaluate the impact of a public child care program in Quebec (Canada), finding that the introduction of generous child care subsidies led to a strong increase in employment among married mothers. For Italy, Del Boca (2002), Del Boca and Vuri (2007) and Del Boca et al (2009) find a positive impact of child care coverage and child care subsidies on the likelihood that the mother works. In particular, Del Boca and Vuri (2007) take into account the impact of rationing, due to child care system rigidity (in terms of accessibility, opening time and costs), and find that in areas with higher child care availability the probability of female employment is higher.

In terms of children's outcomes, while recognizing the importance of the contributions of development psychologists on the impact of child care on non cognitive outcomes, in our discussion we focus more on children's cognitive outcomes in an economic framework. In the economics literature on human capital, Becker (1964) has pointed out that the returns on investments in early childhood are likely to be relatively high, simply because of the long period of time in which to reap the rewards. Carneiro and Heckman (2003) took this argument further, arguing that investments in early childhood have higher returns for children living in disadvantaged contexts. Early childhood educational programs can generate learning gains in the short-run and, in many cases, improve the long-run prospects of children, especially for low income families.

A number of studies for the U.S. show that the evidence regarding this impact is limited to short-run outcomes and that the findings are mixed. Loeb et al (2007), for instance, find that pre-primary education in the U.S. is associated with improved reading and Math skills at primary school entry. Positive effects of child care on children's short-run outcomes are also found by Fitzpatrick (2008), but the impacts depend strongly on ethnicity and family income. Melhuish et al (2008) suggest that children with low educated parents benefit most from child care attendance.

Research from Europe focuses on public child care, which is more widespread than in the U.S., especially in Northern European countries. Datta Gupta and Simonsen (2012) evaluate the impact of child care exposure at age 3 on children's cognitive outcomes at age 11, in Denmark. They find that having attended high-quality pre-school (instead of family day-care) has a positive impact on Language and problem solving tests scores, while it decreases the probability of grade retention. Other studies use information on child care coverage at aggregate level, as we do in this paper. Havnes and Mogstad (2010, 2011b) find that a substantial change in preschool supply in Norway has

\footnotetext{
3 See Blau and Currie (2006) and Ruhm (2004) for excellent surveys.
} 
strong positive impacts on children's outcomes, although the impact is much stronger for children of low educated parents. Their results suggest a positive and significant impact of child care coverage on educational outcomes, such as years of education and college attendance, but also on long-term outcomes, such as adult earnings. Other studies for Latin American provide similar results. Berlinski et al (2009), exploiting the variation on preschool availability induced by a preschool expansion policy implemented in Argentina, estimate that having attended preschool increases third grade Math and Spanish test scores by almost 23 percent of one standard deviation of the scores distribution. Berlinski et al (2008) estimate that the benefits from having attended preschool in Uruguay are small when the child is in primary school but increase when the child grows up.

In Italy, the topic of early childhood intervention and child care impacts on children's outcomes has largely been neglected. Only very recently has there been availability of data on children's outcomes (ISFOL, INVALSI and local data sources referring to specific regions, such as Emilia Romagna), which made it possible to consider the impact of child care not only from the standpoint of physical care but also in terms of its role in educating young children. Del Boca and Pasqua (2010) compare different Italian data sources and show a positive correlation between child care use and subsequent cognitive outcomes of children.

\section{Child care in Italy}

While Italy is ranked quite high for its child care policies for children aged 3-6, it fares much worse for its policies for children under 3: public child care for children aged 3 or older has a utilization rate of 95 percent, whereas public child care for children younger than 3 covers only the 13 percent of children aged 0-2 (ISTAT, 2010).

In Italy, the child care policy for children aged 0-2 is decentralized: the municipality is the main decision maker, while the regions define general management criteria; ${ }^{4}$ the central government is only responsible for defining common objective standards and resources allocation among regions. The division of competences across different political levels may explain the strong differentation across Italian regions: Figure 1 shows that the availability of public child care for children under 3 at the time considered in our analysis (2005) ranges from around 25 per cent in some areas in the North to under 5 percent in most of the South. On average, in 2005, only 8 percent of children aged between 0 and 2 years had access to public child care facilities.

At the end of the 90 s and during the early 2000s, the Italian government was concerned about the very low availability of public services and established a National Fund for regions and municipalities in order to encourage the development of child care services for children aged 0-2. This intervention has defined, for the first time, the educational role of child care and has allowed also the private sector to provide child care services, under regional regulatory frameworks. ${ }^{5}$ As mentioned in a report by the Istituto Degli Innocenti (2006), private child care has developed differently across Italy and is more widespread in areas where public child care is also more developed:

\footnotetext{
4 To date, in Italy there are 8,092 municipalities in 20 regions.

5 Law N. 285/1997 established a National Fund for Early Childhood and Adolescence allowing also the private and third sectors to provide child care services, while Law 448/2001 (Budget Law 2002) defined formal child care as "structures aimed at granting the development and socialization of girls and boys aged between 3 months and 3 years and to support families and parents with young children".
} 
this pattern is also confirmed by Figure 2, reporting a positive and significant correlation between the availability of public and private child care facilities. This correlation could be due to the practice adopted by local authorities of combining their supply with one of the private services to increase child care availability (Antonelli and Grembi, 2010). In fact, the municipalities can outsource several services (canteen, transportation, etc), they can book a certain number of slots in private facilities or they can allow for private providers to manage part of their supply, while the access to and the price of the service stands under the control of the public administration.

The municipalities' decisions concerning the number of child care slots to offer depend on their preferences, as to which types of household to target, and on their budget constraint. Each municipality establishes eligibility requirements so that the number of available slots can be assigned to households that may benefit more.

While absolute priority is given to applications of children with disability, ${ }^{6}$ the other criteria can be classified into two main categories. The first category includes criteria related to the socio-economic conditions of the household, such as being an orphan or a fostered child, having one or both parents unemployed, living with a single parent. The second category refers mainly to the employment conditions of both parents and may include criteria such as having both parents working or having parents with a commute to work. Thus, according to these access criteria, public child care can be viewed both as a support for the early education and the social inclusion of children from disadvantaged environments or as a tool to help families to reconcile work and parenthood during the childbearing years. Among all the eligibility criteria, household income plays a very significant role and it has been found to be crucial for admission to public child care centers in about half of the municipalities (Pavolini and Arlotti, 2013). If there are two households with similar working conditions but different economic resources, the selection will give a higher score to the one with less resources.

From the social planner's point of view, both outcomes are particularly important for Italy. On one hand, in fact, among low income households, there is a growing number of children from immigrant families, whose social integration may be favored by child care attendance. On the other hand, nearly 30 percent of mothers leave their jobs after the birth of the first child, and the probability of leaving the labor market after childbirth is higher for low educated mothers and in areas with limited child care (Bratti et al, 2005; Pronzato, 2009). In areas where fewer slots are available, criteria rules become more relevant. In this case the social planner can select households, which may benefit more from the policy, either providing to mothers an alternative form of care if they want to work or offering to children coming from disadvantaged backgrounds better educational inputs.

\section{Theoretical Framework}

In this section, we present a framework that can help to interpret our econometric models and results. The municipalities' decision regarding the supply of child care slots depends on the local budget constraint and preferences of the local government. We assume that local governments aim to encourage women's work (which would also

\footnotetext{
6 National Law 104/1992.
} 
increase the tax base that can be used to pay for local services, including child care) and to increase the educational outcomes of children through public child care.

The objective of the municipality is given by

$$
U(L, E)
$$

where $L$ is the participation of mothers (of young children) and $E$ is an indicator of the educational outcomes of children in the local area. The social planner seeks to maximize her objective by manipulating (final) demand, which is accomplished by using the policy variables at her disposal. We assume that the policy variables are: $N$, the number of public child care slots; $P$, the price charged each household for a slot; and $R$, the rules used to assign slots to potential applicants in the case of excess demand at the price $P$. In this simple model, we assume that the price $P$ is the same for all households. Given the population of potential applicants (mothers with young children), there exists a set of households that would gain access to public childcare under $(N, R, P)$. In this set of households, we say that the number $L^{*}(N, R, P)$ would work and that the educational outcome of all children is given by $E^{*}(N, R, P)$. Hence, the social planner solves the following maximization problem:

$$
\max _{N, R, P} U\left(L^{*}(N, R, P), E^{*}(N, R, P)\right)
$$

We now consider the constraints on the social planner's choices. A social planner may use rationing as a means to maximize her objective function. For example, if the social planner wants to increase maternal employment, she could do so by limiting access and making maternal employment one of the criteria for acquiring a slot. Different rationing criteria may be utilized if the social planner wants to increase the educational outcomes of children in this population. Viewed in this way, rationing and selective access are outcomes of a mechanism design implemented by the social planner. The monetary constraint the social planner faces is given by

$$
C \times N=S+P \times N
$$

where $C$ is the cost of each child care slot sustained by the municipality; $S$ are the fixed subsidies that the central government has allocated to the local government; and $P$, the price per slot sustained by the family. Hence, the number of slots the social planner can provide given $S$ and $P$ is

$$
N=S /(C-P)
$$

As the social planner increases the price $(P)$, the number of slots increases. We assume that for any $N$, potential demand is such that there exists a $P^{*}(N)$ allowing demand to exactly equal supply $(N)$ at that price. In this case, the price serves to "ration" demand, and the rules $R$ are irrelevant: only households with a willingness to pay for child care greater than or equal to $P^{*}$ would get a slot. This implies that, in such cases, only households 
with a higher income or those highly valuing child care would be able to pay for this service. Thus, at any $P$ less than $P^{*}(N)$, there will be excess demand and the rationing rules become operative, selecting applicants whose characteristics and choices the social planner values. By lowering the price and creating excess demand, the social planner can choose individuals who acquire the slots instead of having the "market" to do this strictly through the price mechanism. However, there is a cost to this selection, in that fewer slots can be generated. Even though eligibility requirements may be different across local areas, producing mixed types of eligible households, we expect that when child care coverage is rationed, it has a stronger impact on mothers' working status and on children's educational outcomes, since it selects groups which are more likely to benefit from the services.

Unfortunately, the data useful to fully estimate this model are not available. In particular we do not have data on child care prices at the provincial level. Nevertheless, we believe that the model described above can be a background framework, which can help us to interpret the results from the empirical analysis.

\section{Empirical strategy}

In this section we present our empirical strategy to estimate the effect of public child care availability on mothers' probability to work and children's cognitive outcomes when the child is in second grade at primary school. The equations we estimate are defined as follows:

$$
\begin{gathered}
L_{i p}=\alpha_{0}+X_{i p}^{\prime} \alpha_{1}+H_{i p}^{\prime} \alpha_{2}+\alpha_{3} N_{p}+W_{p}^{\prime} \alpha_{4}+\nu_{i p} \\
E_{i p}=\delta_{0}+X_{i p}^{\prime} \delta_{1}+H_{i p}^{\prime} \delta_{2}+\delta_{3} N_{p}+W_{p}^{\prime} \delta_{4}+\phi_{i p}
\end{gathered}
$$

where $L_{i p}$ is a binary variable equal to 1 if the mother of child $i$ in province $p$ works, and $E_{i p}$ is the cognitive outcome of child $i$ in province $p$, measured by the scores in Language and Math tests. $X_{i p}$ and $H_{i p}$ represent children's and parents' observable characteristics, while $W_{p}$ is a vector of control variables at provincial level.

The main variable of interest is $N_{p}$ which is public child care coverage at the level of the province (defined as the number of available slots per child, multiplied by 100). We view this as an indicator of the likelihood that the child attended child care. The coefficients $\alpha_{3}$ and $\delta_{3}$ in equations (1) and (2) represent reduced form estimates of the effects of a percentage change in child care availability on all children, including any indirect and spillover effects. Hence, we identify the Intention to Treat effect (ITT) rather than the effect of having attended public child care (the effect of the Treatment on the Treated - TT). The identification of the effects of interests relies on cross-sectional variation in child care coverage across provinces.

Apart from the observable characteristics $X_{i p}, H_{i p}$ and $W_{p}$, there are other unmeasured characteristics of the household, the child, and the province where the household resides, which are important determinants of the mothers' labor market participation and children's cognitive outcomes and which are reflected in the disturbance term $\epsilon_{i p}$ and $\varepsilon_{i p}$. The disturbances have a group structure and are defined as follows: 


$$
\begin{aligned}
& \epsilon_{i p}=\alpha_{p}+\omega_{i p} \\
& \varepsilon_{i p}=\delta_{p}+v_{i p}
\end{aligned}
$$

where $\alpha_{p}$ and $\delta_{p}$ are province-specific components, while $\omega_{i p}$ and $v_{i p}$ are disturbances at the individual level.

We estimate the above equations using both OLS and GLS (or Random Effects -RE) models, in order to take into account the error components at provincial level. Moreover, since we are using mixed-level data, including information at the individual and provincial levels, we adopt cluster-adjustments of the estimates of the standard errors to account for non-independence of observations within the same province.

These strategies provide consistent estimates of the child care effects if the error components (at individual and provincial levels) are uncorrelated with the included regressors. Using the aggregate number of slots available in the local area allows us to claim that there is little scope for endogeneity between the child care measure and the individual component of the disturbance terms in any equation. However, there is a plausible risk of omitted variables at the provincial level: child care coverage at provincial level may be correlated with unobserved characteristics of the province and of the individuals living in each province. If this is the case, the coefficients of interests in equations (1) and (2) are biased and inconsistent. We try to take into account this issue including province-level regressors that reflect provincial characteristics, as summarized in the vector $W_{p}$. All these factors may be correlated with provincial child care coverage and may have a direct influence on the outcomes of interest.

As a sensitivity analysis, we consider another specification, in which we include provincial fixed effects that capture the effects of all unobservable characteristics of the province, which may affect our outcomes. We also use a Mundlak-type specification of our GLS model, where the province unobserved component is a function of provincial averages of individual variables, to test the significance of the correlation between provincial and individual characteristics. ${ }^{7}$

\section{Data and Variables}

We use individual data on children's primary school outcomes in conjunction with information regarding public child care coverage at the provincial level. Table 1 gives the definition of each variable, while Table 2 provides some descriptive statistics.

Data on children's cognitive outcomes come from from the Italian Institute for the Evaluation of the Education System (INVALSI) for 2009-2010. Since the school year 2008-09, INVALSI and its National Evaluation Service (SNV) provide the only ongoing national survey of students' educational achievements at primary school. These assessments measure the abilities of students in second, fifth and sixth grades (ISCED levels 1 and 2). In addition to

7 We thank an anonymous referee for suggesting this methodology. 
test scores, INVALSI provides information on children's and parents' characteristics reported by the schools. Thus, the data include individual-level covariates indicating gender, citizenship, parents' working status and education. ${ }^{8}$

For our analysis, we rely on data concerning second grade students in the school year 2009-10, which is the most appropriate cohort to which we can match data on child care availability. In this survey, INVALSI assessed the overall population of students enrolled in the second grade and designed a sample of schools and students that performed the tests under the supervision of an external inspector. Since there has been evidence of cheating behavior during the test in not sampled schools (INVALSI, 2011), we focus our analysis only on sampled schools and students in order to improve the reliability of the results. Out of 462,960 observations in second grade, the final sample includes students in sampled schools that took both the Language and Math tests, yielding a sample of 33,708 observations. In the estimation of the mothers' work equation we end up with 25,287 observations, for which data on mothers' employment and education are not missing.

We consider three dependent variables. The first is a dummy equal to one if the child's mother works when the child is enrolled in second grade (aged 7 years, if regular in his school path), and equal to zero otherwise. As we can see from Table 2, almost 60 percent of children in the sample has the mother participating in the labor market. The other two dependent variables refer to children's scholastic achievements in Language and Math tests. Since these tests are composed of multiple-choices questions, the final test score is built as a percentage of correct answers over the total number of questions. As shown in Table 2, children perform better in Language than in Math: the average test score in Language is 62.2 , while the average score in Math is only 57.3.

Child care coverage is defined as the ratio between public child care slots and the population aged 0-2 years (multiplied by 100), by province. The data refer to 2005 and are taken from Cittadinanzattiva (Cittadinanzattiva, 2007), an independent organization that runs yearly surveys to monitor the supply of public services, such as child care. Specifically, Cittadinanzattiva gathers the information on the number of slots available for each municipality from the Ministry of Interior and then reports the number of slots for each province. The variable of interest has been constructed dividing the number of slots available in each province by the population aged 0-2 in the same year; this variable includes only public child care services, i.e., publicly provided services in publicly owned facilities (Cittadinanzattiva, 2007). ${ }^{9}$ It would be preferable to use data on child care availability in 2004, when the children were 2 years old. However, the only source of data on child care coverage in Italy with a sufficiently disaggregated level of information is the one provided by Cittadinanzattiva and referred to $2005 .{ }^{10}$ We will investigate the role of this time mismatch in the robustness analysis.

\footnotetext{
8 The INVALSI wave 2009-10 that we are using actually contains a question regarding individual child care attendance during infancy. However, this information cannot be used in a credible manner, since it is characterized by almost 40 percent of missing values.

9 In Italy there can be three types of child care provision: the first one refers to the cases where the public entity (i.e, the municipality) is both the owner and the provider of the service; the second, instead, refers to the cases where the municipality is the owner of the facility but outsources the provision of the service to other private entities; finally, there may be some cases where the private sector is both the owner and the provider of the service. For this analysis we use data concerning the first type of management.

10 The other official sources of information on child care coverage at aggregate level are ISTAT (Italian National Statistical Institute) and Istituto Degli Innocenti, but both provide information only at regional level for the period relevant for this study.
} 
On average public child care covers 8 children out of 100 . According to Table 2, child care availability varies markedly across Italian provinces, ranging from values close to 0 to more than 25 percent.

As reported in Table 1, we use several control variables at individual level, exploiting the information gathered by INVALSI. Specifically, we control for children's gender and citizenship, mothers' and fathers' education, as well as for whether the child has some individual or family information missing. ${ }^{11}$ As Table 2 shows, fifty percent of the children are male, and 8 percent of them are immigrant. The observations with missing information on family characteristics represent almost 25 percent of the sample and missing data on children's personal characteristics are almost 3 percent.

Finally, we use other variables at the province level to control for provinces' characteristics. As a general indicator for the wealth of the province, we include GDP per capita. The enrollment rate of 3-5 years old children in pre-primary school during the school year 2006-07, together with the percentage of private primary schools, the average school size for each province and its square, as well as the percentage of graduates over the population reflect provincial characteristics related to the education system and to the overall expenditure for all levels of education. In order to capture provincial characteristics related to labor market opportunities for women, we include variables describing the composition of labor demand: the provincial employment rate in public services and in health or social services. Apart from the information on the school characteristics, all controls at the provincial level refer to the year of childbirth or before the period to which the analysis refers.

Figures 3 and 4 report the correlations between child care coverage and the outcomes of interest at regional level. Regions with higher child care coverage are characterized by a higher employment rate of mothers and better results in Language test scores, while there is no statistically significant relationship between child care coverage and Math test scores.

\section{Results}

\subsection{Baseline specification}

Table 3 reports the results for our three dependent variables. For each variable, we estimate both the OLS and GLS specifications. We find a positive and significant effect of child care on both mothers' employment status and Language test scores with both specifications, while no effect is found for Math. ${ }^{12}$

Column (a) shows the coefficients on mothers' work. The coefficients of child care coverage are positive and statistically significant: according to the results from the GLS estimation, an increase of 10 percentage points in child care coverage increases mothers' probability of working by 13 percentage points.

\footnotetext{
11 The dummy variable "Child missing information" indicates whether a child's gender or citizenship is not available in the data; the dummy variable "Family missing information" is equal to one if a mother's or a father's employment or education are missing. 12 Concerning the estimation on mothers' working status, results do not differ using probit or logit instead of OLS and GLS. Results are available upon request from the authors. When estimating the mothers' work equation with OLS and GLS we also correct the standard errors for heteroskedasticity.
} 
In columns (b) and (c) of Table 3 the coefficients on Language and Math test scores are reported. According to the results for Language test scores, one percentage increase in child care availability is associated with an increase in Language test scores of around 0.2 points, corresponding to 0.85 percent of a standard deviation of the scores distribution. This parameter represents an Intention to Treat (ITT) effect of public child care, i.e., an effect on average for all children in the same province, including any indirect and spillover effects. To move from the ITT to the TT effect, one has to know the probability of being treated and this is not straightforward in this context, where the probability of attending child care depends not only on parental preferences but also on eligibility criteria. However, we can provide some simple intuition to better understand the size of this effect. Suppose a population of 100 children where 8 percent attends public child care. Increasing child care availability by 1 percent means that, after the policy change, 9 percent of children attend public child care. The change results in an average increase in test scores by 0.195 over 100 children. If this change is only driven by the additional child enrolled in child care, the effect of the additional slot on the treated child would be equal to a 19.5 points increase in the Language test scores, which corresponds to 0.85 of one standard deviation of the scores distribution, and it is much larger than the results previously found in the literature. For instance, Berlinski et al (2009) use a similar econometric model and show that an additional preschool place per child in Argentina increases third grade Math and Spanish test scores by 0.23 of one standard deviation of the scores distribution. For the U.S., Loeb et al (2007) find that having attended child care in the year before kindergarten increases Reading and Math scores at kindergarten by 0.12 of one standard deviation; however, they also find greater benefits for children with very low levels of income and for children entering child care centers between age 2 and 3.

The stronger effect found in this study may be due to several reasons. The first one relates to the age of intervention. We analyze child care for children younger than 3, while the other studies refer to preschool or prekindergarten programs for different ages of entry at center-based child care. Loeb et al (2007) find that children entering earlier benefit more from child care attendance. Early investments are not only more important per se, but facilitate the productivity of later investments, as pointed out by Cunha et al (2006). Skill attainment at one stage of the life cycle raises skill attainment at later stages of the life cycle. Even though we are observing children after only a few years from the child care intervention, the same input received by the child at pre-primary or primary school may have a different productivity according to whether the child attended or not formal child care before turning 3 years old. Second, the estimated effect is very likely to be local and to affect only a specific part of the children's scores distribution. As we have seen in Section 3, the additional slot (especially when child care availability is low) is not allocated on a first-come first-served basis but by using eligibility criteria, which may give priority to children who may have higher benefits from attending formal child care. Indeed, we will further analyze this issue in Section 7.2, where we allow for non-linear child care effects.

Finally, since the estimated effect is an ITT effect, it may also incorporate some other channels, such as peer and spillover effects and effects due to related policies. In order to see how much of the estimated effect can be explained by these other mechanisms, we work through simulations. Let's first consider an example of peer effects. 
Suppose that 99 children face a peer effect equal to 1/100 of the effect on the treated child. In this case, the overall effect that we found includes the effect on the treated child plus the effects on all other children. The effect on the treated child thus would correspond to 9.79 points, equal to 0.43 standard deviations. Let us now consider other effects due to related policies, such as private child care. As shown in figure 2 , there is a positive correlation between public and private child care centers. This could be due to the fact that the social planner can increase the availability of child care not only through the direct provision of an additional place, but also reserving or subsidizing slots in private facilities. Including this additional channel, and assuming that private child care has the same effect on child development than the public one, the final effect of an additional place in public child care on the treated child would be equal to 13 points, corresponding to 0.56 standard deviations. $^{13}$ If we bring the two channels together (i.e., peer effects and private child care), we find that the effect on the treated child would correspond to an increase in the Language test scores by 7.84 points, equal to 0.34 of one standard deviation. However, we are aware that if either the peer effects or the positive correlation between public and private services are due to unobserved characteristics of the people in the province also influencing children's cognitive development, our estimates are then biased and inconsistent. We try to address this issue in the robustness section below.

Concerning the other independent variables, children's gender is not significantly associated with mothers' working status, but boys achieve, on average, higher scores in Math and lower scores in Language. Immigrant status does matter for all the dependent variables: mothers of non-Italian children are less likely to work than those of the Italian ones and immigrant children perform worst in both Language and Math tests. Mothers' working status is strongly and significantly associated with mothers' education, confirming previous results in this strand of the literature, especially for Italy (Del Boca et al, 2009). The same is true for fathers' education. Both paternal and maternal education have a positive and significant impact on children's test scores. Among other controls at provincial level, GDP has a positive effect on mothers' employment status while all other variables (with the only exception of private primary schools) do not influence mothers' working status. GDP is also positively and significantly correlated with both Language and Math test scores.

\subsection{Non-linearity in child care impacts}

In order to test whether the effects of child care coverage differ across the child care coverage distribution, we repeat the baseline analysis using a non-linear specification. More precisely, we estimate equations (1) and (2) adding a quadratic term of child care coverage. The results, reported in Table 4, show that the relationship between child care coverage and both mothers' employment and children's Language test scores has a concave form, implying that the effect of a percentage change in child care coverage is higher when the availability of the service is scarce. Again, we do not find any effect on Math score.

The greater child care effect found in areas where child care coverage is less available may be due to the strength of rationing, so that in provinces where the availability of child care is lower, local authorities may

13 We assume that one more public child care center corresponds, on average, to 0.5 private child care center. 
use access criteria targeting the service to households who may benefit more from it. This is also in line with the theoretical framework proposed in Section 4. However, the results may also indicate a diminishing marginal productivity of public child care as long as the availability of the service increases. The limitations of our data prevent us from clearly disentangling these effects.

\subsection{Robustness checks}

\subsubsection{Provincial unobserved heterogeneity}

The estimates of the child care impacts presented in Section 7.1 are likely to be biased if public child care availability is correlated with unobservable characteristics of the province and of the individuals living in that province, which we cannot account for. Thus, we use a further specification where we estimate the effects of public child care with OLS and province fixed effects. Results are reported in Table 5 and are consistent with the ones found in the main analysis.

To control whether the main results are also sensitive to the potential correlation between parents' and provinces' unobservables, we estimate a GLS model with a Mundlak-type specification, where provincial unobserved heterogeneity is assumed to be a function of provincial averages of individual characteristics. Results are shown in Table 5 and are very similar to the ones reported in Table 3. Since some of the variables in the Mundlak specification affect the outcomes significantly, this may suggest that a model with province fixed effects should be preferred.

\subsubsection{Missing data on family characteristics, sample heterogeneity and time mismatch}

Since we estimate the participation equation keeping only observations without any family information missing, we also repeat the analysis for the test score equations keeping the same subsample used to estimate equation (1). Results are presented in Table 6, panel (a). The coefficients are very similar to the ones presented in Table 3 , confirming that missing data are not systematically linked with our analysis and do not bias the results.

In order to make sure that results are not driven by provinces with very high/low levels of child care coverage, we repeat the estimation considering subsamples identified through the child care coverage distribution. In Table 6, panel (b) we replicate the analysis dropping provinces where child care is lower than the 10th percentile (corresponding to 1.16 percent); in panel (c) we drop provinces where child care coverage is higher than the 90 th percentile of the distribution (corresponding to 16 percent). ${ }^{14}$ Results are confirmed in all cases.

\footnotetext{
14 We also performed a robustness check (not reported here) excluding provinces in the Emilia Romagna region, which is characterized by very high child care availability with respect to other regions and with respect to the Italian average. Results are very close to the ones presented in Table 6, panel (c).
} 
We also check for sample heterogeneity, in particular concerning the age of children when the outcomes are measured. In Table 6, panel (d), we replicate the analysis keeping only students regular in their school path and aged 7 years in 2009-10. ${ }^{15}$ Also in this case, results do not differ from the ones presented in table 3.

The measure of child care coverage that we have at our disposal does not exactly correspond to the true child care availability faced by children enrolled in the second grade in 2009-10. In fact, the children in our sample would have been aged 0-2 years in 2004, one year before the time to which the child care measure refers. To test whether this discrepancy affects our estimates, we repeat the estimation of the model using data from the 2008-09 wave of INVALSI data. Also in this case, we keep only schools and students that took the test under the supervision of an external inspector. Since children in this school year would have been aged 0-2 in 2003, they are more distant in time from our measure of child care coverage and we expect a greater effect of measurement error in this case. The results from this test are presented in Table 6, panel (e): in this case, the coefficients for all the dependent variables are slightly lower than the ones found using 2009-10 data. While this pattern provides evidence of an attenuation bias induced by measurement error, it also seems that it does not affect the estimates significantly.

\section{Conclusions}

In this paper we estimate the effect of public child care coverage on mothers' working status and children's school performances at primary school. Using INVALSI data for the school year 2009-10, in conjunction with data on child care coverage at the province level, we find a positive child care effect on mothers' working status as well as on Language test scores. Our estimates indicate that a percentage change in public child care coverage increases mothers' probability to work by 1.3 percentage points and children's Language test scores by 0.85 percent of one standard deviation of the scores distribution, while we do not find any effect on Math test scores. These results are robust to the inclusion of province dummies and to several specification and robustness checks.

We estimate a non-linear specification of the base model, finding that the relationship between child care coverage and, respectively, mothers' work and Language test scores is actually concave. When child care availability is low, the effect of a percentage change in child care on both mothers' working status and children's Language test scores is stronger, indicating a potential effect of selection criteria of households more responsive to child care.

Future research will analyze more closely the actual rationing mechanisms of child care "market" in which the crucial actors are the municipalities deciding on the supply of child care slots and the households with young children applying for a slot. A better understanding of these mechanisms may also help in analyzing child care policies and, in particular, the effects not only of increasing child care availability but also of changing eligibility criteria.

Acknowledgements The authors acknowledge financial support from Collegio Carlo Alberto (project "Parental and Public Investments and Child Outcomes") and from the Europen Union's Seventh Framework Programme (FP7/2007-2013) under grant 15 INVALSI data provide information on whether the child is regular in his school path or held back before or enrolled in a higher grade with respect to children of the same age. 
agreement no. 320116 for the research project FamiliesAndSocieties. We would like to thank Christopher Flinn, Cristian Bartolucci, Ignacio Monzon, Francesco Figari, Mario Pagliero, Vincenzo Galasso, Daniela Vuri, Elena Meschi, Claudio Lucifora, Marco Francesconi, Chiara Monfardini and Silvia Pasqua and seminar participants at DONDENA (Bocconi University), CHILD and 4th IDW (Collegio Carlo Alberto), NYU, CHILD-RECENT (University of Modena) and the Catholic University Milan for useful suggestions and comments. We also thank the editor and two anonymous referees for their helpful suggestions. We are also grateful to Piero Cipollone (Bank of Italy) and Patrizia Falzetti (INVALSI) for providing the data.

\section{References}

Antonelli MA, Grembi V (2010) The more public the more private? The case of the Italian child care. CREI WP No 3

Baker M, Gruber J, Milligan K (2008) Universal child care, maternal labour supply and family well-being. Journal of Political Economy 116(4):709-745

Becker G (1964) Human Capital: A Theoretical and Empirical Analysis, With Special Reference to Education, 1st edn. University of Chicago Press, Boston, MA.

Berlinski S, Galiani S, Manacorda M (2008) Giving children a better start: preschool attendance and school-age profiles. Journal of Public Economics 92:1416-1440

Berlinski S, Galiani S, Gertler P (2009) The effect of pre-primary education on primary school performance. Journal of Public Economics 93:219-234

Blau D, Currie J (2006) Pre-school, day care, and after-school care: Who's minding the kids? In: Hanushek EA, Welch F (eds) Handbook of The Economics of Education, vol 2

Bratti M, Del Bono E, Vuri D (2005) New mothers 's labour force participation in Italy. LABOUR 19:79-121

Carneiro P, Heckman JJ (2003) Human capital policy. In: Heckman JJ, Krueger AB, Friedman BM (eds) Inequality in America: What Role for Human Capital Policies?, MA: MIT Press, Cambridge, pp 77-239

Cascio E (2009) Maternal labor supply and the introduction of kindergarten in American public schools. Journal of Human Resources 44:140-170

Cittadinanzattiva (2007) Gli asili nido comunali in Italia, tra caro rette e liste d'attesa: Dossier a cura dell'Osservatorio Prezzi e Tariffe di Cittadinanzattiva. Cittadinanzattiva, Rome

Cunha F, Heckman J, Lochner L, Masterov D (2006) Interpreting the evidence on life cycle skill formation. In: Hanushek EA, Welch F (eds) Handbook of the Economics of Education, Amsterdam: North-Holland, pp 697-812

Datta Gupta N, Simonsen M (2012) The effects of type of non-parental child care on pre-teen skills and risky behavior. Economics Letters 116(3):622-625

Del Boca D (2002) The effect of child care and part time opportunities on participation and fertility decisions in Italy. Journal of Population Economics 15(3):549-573

Del Boca D, Pasqua S (2010) Esiti scolastici e comportamentali, famiglia e servizi per l'infanzia. FGA Working Paper No $36 / 2010$ 
Del Boca D, Vuri D (2007) The mismatch between employment and child care in Italy: the impact of rationing. Journal of Population Economics 20(4):805-832

Del Boca D, Pasqua S, Pronzato C (2009) Motherhood and market work decisions in institutional context: a European perspective. Oxford Economic Papers 61(Suppl. 1):i147-i171

EU (2002) Presidency Conclusions. Barcelona European Council 15 and 16 March 2002

Fitzpatrick MD (2008) Starting school at four: The effect of universal pre-kindergarten on children's academic achievement. BE Journal of Economic Analysis and Policy 8(1 (Advances)):1-38

Havnes T, Mogstad M (2010) Is universal child care leveling the playing field? Evidence from non-linear differencein-differences. IZA Discussion Paper No 4978

Havnes T, Mogstad M (2011a) Money for nothing? Universal child care and maternal employment. Journal of Public Economics 95(11-12):1455-1465

Havnes T, Mogstad M (2011b) No child left behind: Subsidized child care and children's long-run outcomes. American Economic Journal: Economic Policy 3(2):97-129

Heckman JJ, Stixrud J, Urzua S (2006) The effects of cognitive and noncognitive abilities on labor market outcomes and social behavior. Journal of Labor Economics 24(3):411-482

Istituto Degli Innocenti (2006) I nidi e gli altri servizi educativi integrativi per la prima infanzia. Rassegna coordinata dei dati e delle normative nazionali e regionali al 31/12/2005. Quaderni del Centro Nazionale di Documentazione e Analisi per l'Infanzia e l'Adolescenza n. 36.

INVALSI (2011) Rilevazione degli Apprendimenti - SNV Prime Analisi A.S. 2009/2010. Istituto Nazionale per la Valutazione del Sistema Educativo di Istruzione e di Formazione

ISTAT (2010) L'offerta comunale di asili nido e altri servizi socio-educativi per la prima infanzia. Anno Scolastico 2008/2009. Istituto Nazionale di Statistica

Loeb S, Bridges M, Bassok D, Fuller B, Rumberger RW (2007) How much is too much? The influence of preschool centers on children's social and cognitive development. Economics of Education Review 26:52-66

Melhuish E, Sylva K, Sammons P, Siraj-Blatchford I, Taggart B, Phan M, Malin A (2008) Preschool influences on mathematics achievement. Science 321:1161-1162

OECD (2007) PISA 2006 Science Competencies for Tomorrow's World

OECD (2010) OECD Family Database. Available at www.oecd.org/els/social/family/database

Pavolini E, Arlotti M (2013) Growing unequal: child care policies in Italy and the social class divide. mimeo University of Macerata

Pronzato C (2009) Return to work after childbirth: does parental leave matter in Europe? Review of Economics of the Household 7:341-360

Ruhm C (2004) Parental employment and child cognitive development. Journal of Human Resources XXXIX:155192 
Figures and Tables

Fig. 1 Child care coverage across Italian regions (slots over population 0-2 years), 2005.

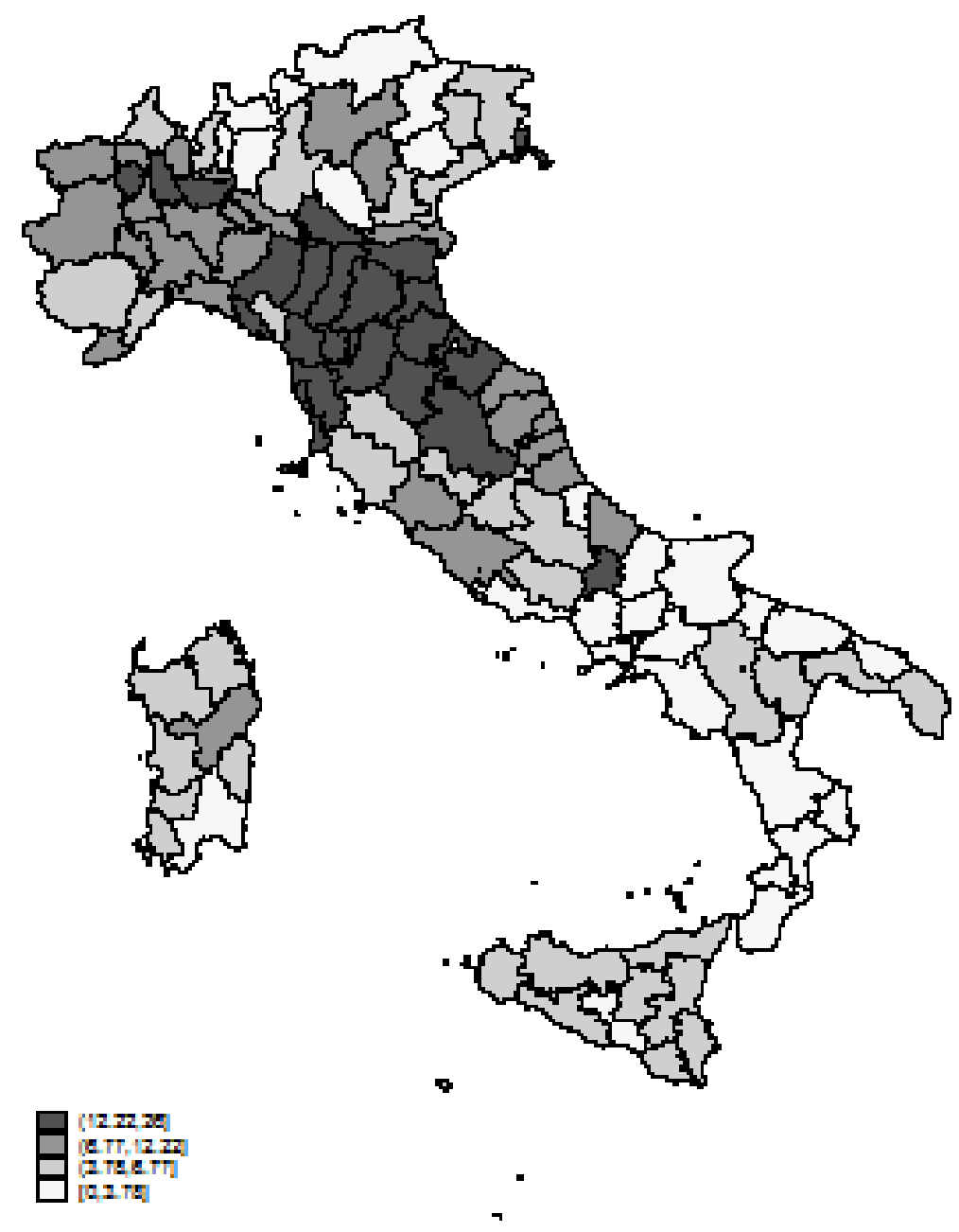

Source: own elaborations from Cittadinanzattiva (2007). 
Fig. 2 Correlation between public and private child care centers in 2003 (absolute numbers).

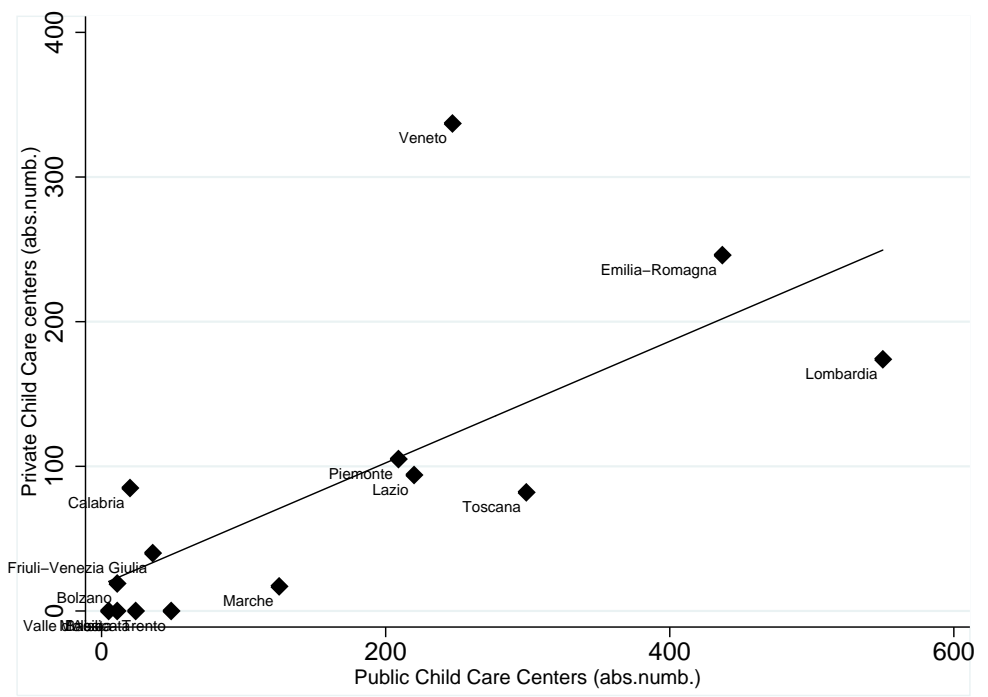

Notes. Correlation coefficient: 0.7139; p-value: 0.0041. Own elaborations from Istituto Degli Innocenti (2006).

Fig. 3 Correlation between mothers' working status and child care coverage, by region.

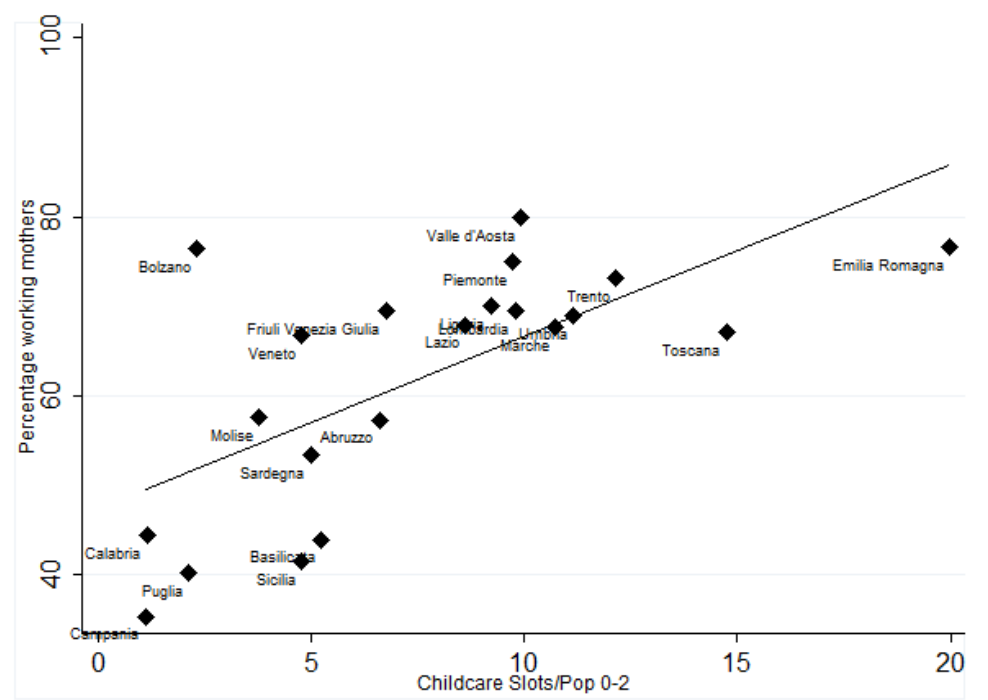

Notes. Correlation coefficient: 0.6702; p-value: 0.0009. Own elaborations from INVALSI SNV 2009-10 and Cittadinanzattiva (2007). 
Fig. 4 Correlation between Language and Math test scores and child care coverage, by region.
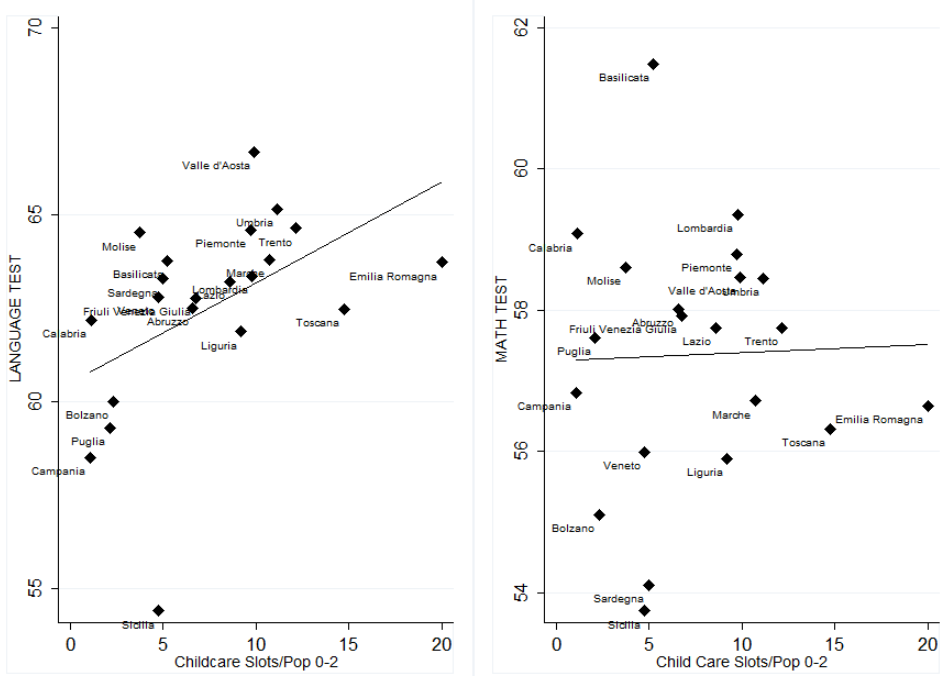

Notes. Correlation coefficients: for Language 0.4787 (p-value 0.0282); for Math 0.0301 (p-value 0.8969). Own elaborations from INVALSI SNV 2009-10 and Cittadinanzattiva (2007).

Table 1 Definitions of variables

\begin{tabular}{|c|c|c|}
\hline & Description & Source \\
\hline \multicolumn{3}{|l|}{ OUTCOME VARIABLES } \\
\hline Mother's working status & Dummy equal to 1 if the mother works (2009-10) & INVALSI SNV \\
\hline Language test score & Percentage of correct answers in Language test (2009-10) & INVALSI SNV \\
\hline Math test score & Percentage of correct answers in Math test (2009-10) & INVALSI SNV \\
\hline \multicolumn{3}{|l|}{ CHILD CARE VARIABLES } \\
\hline Child care coverage & Public child care slots over population 0-2 years by province $(2005)\left({ }^{*} 100\right)$ & CITTADINANZATTIVA \\
\hline \multicolumn{3}{|c|}{ CONTROL VARIABLES (INDIVIDUAL LEVEL) } \\
\hline Male & Dummy equal to 1 if male & INVALSI SNV \\
\hline Non-Italian & Dummy equal to 1 if the child has not Italian citinzenship & INVALSI SNV \\
\hline Father tertiary education & Dummy equal to 1 if the father has tertiary education & INVALSI SNV \\
\hline Mother tertiary education & Dummy equal to 1 if the mother has tertiary education & INVALSI SNV \\
\hline Family information missing & Dummy equal to 1 if the child has family information missing & INVALSI SNV \\
\hline Child information missing & Dummy equal to 1 if the child has individual information missing & INVALSI SNV \\
\hline \multicolumn{3}{|c|}{ CONTROL VARIABLES (PROVINCE LEVEL) } \\
\hline GDP per capita & Gross Domestic Product per capita (2008 Hundreds Euro) & CAMERA DI COMMERCIO \\
\hline Pre-Primary enrollment rate & Percentage of children aged 3-5 enrolled at Pre-Primary School (2006-07) & MIUR \\
\hline Private Primary Schools & Percentage of private primary schools over total schools $(2008-09)$ & INVALSI SNV \\
\hline School size & Average number of students in Second Grade (2009-10) & INVALSI SNV \\
\hline Graduates & Percentage of graduates over all population (2001) & CENSUS \\
\hline Employment rate Public Services & Percentage of employed in public services over total employment (2001) & CENSUS \\
\hline Employment rate Health-Social Services & Percentage of employed in health/social services over total employment (2001) & CENSUS \\
\hline
\end{tabular}


Table 2 Descriptive Statistics

\begin{tabular}{lccccc}
\hline & Mean & SD & Median & Min & Max \\
\hline Outcome Variables & & & & & \\
\hline Mother's working status & 0.60 & 0.48 & 1 & 0 & 1 \\
Language test score & 62.20 & 22.96 & 65.38 & 3.84 & 100 \\
Math test score & 57.26 & 18.68 & 57.14 & 3.57 & 100 \\
\hline Child care Variables & & & & & \\
\hline Child care coverage & 7.98 & 5.81 & 6.58 & 0.32 & 25.47 \\
\hline Control Variables & & & & & \\
\hline Male & 0.51 & 0.50 & 1 & 0 & 1 \\
Non-Italian & 0.09 & 0.28 & 0 & 0 & 1 \\
Father tertiary education & 0.15 & 0.36 & 0 & 0 & 1 \\
Mother tertiary education & 0.18 & 0.39 & 0 & 0 & 1 \\
Family information missing & 0.25 & 0.43 & 0 & 0 & 1 \\
Child information missing & 0.03 & 0.17 & 0 & 0 & 1 \\
\hline GDP per capita & 226.19 & 57.73 & 234.37 & 127.31 & 367.632 \\
Pre-Primary enrollment rate & 75.65 & 2.77 & 75.60 & 67.65 & 83.66 \\
Private Primary Schools & 22.31 & 20.03 & 17.95 & 0 & 100 \\
School size & 84.824 & 16.57 & 86.35 & 39.11 & 125.36 \\
Graduates & 7.85 & 1.87 & 7.68 & 4.41 & 12.92 \\
Employment rate Public Services & 5.27 & 1.13 & 5.12 & 3.26 & 8.21 \\
Employment rate Health-Social Services & 6.84 & 0.99 & 6.78 & 4.617 & 9.53 \\
\hline
\end{tabular}

Table 3 Estimates from the base model: OLS and GLS specifications.

\begin{tabular}{lcccccc}
\hline & \multicolumn{2}{c}{ (a) Mother's } & working status & (b) Language test score & \multicolumn{2}{c}{ (c) Math test score } \\
\hline & OLS & GLS & OLS & GLS & OLS & GLS \\
\hline Child care coverage & $0.015 * * *$ & $0.013 * * *$ & $0.233 * * *$ & $0.195 * * *$ & -0.010 & -0.001 \\
& $(0.002)$ & $(0.002)$ & $(0.062)$ & $(0.069)$ & $(0.042)$ & $(0.055)$ \\
Male & -0.000 & -0.001 & $-2.567 * *$ & $-2.531 * * *$ & $1.606 * * *$ & $1.642 * * *$ \\
& $(0.006)$ & $(0.006)$ & $(0.256)$ & $(0.252)$ & $(0.253)$ & $(0.254)$ \\
Non-Italian & $-0.286 * * *$ & $-0.311 * * *$ & $-15.289 * * *$ & $-15.660 * * *$ & $-7.264 * * *$ & $-7.310 * * *$ \\
& $(0.020)$ & $(0.018)$ & $(0.576)$ & $(0.565)$ & $(0.523)$ & $(0.512)$ \\
Father tertiary education & $0.059 * * *$ & $0.058 * * *$ & $5.774 * * *$ & $5.813 * * *$ & $3.644 * * *$ & $3.743 * * *$ \\
& $(0.014)$ & $(0.014)$ & $(0.400)$ & $(0.397)$ & $(0.409)$ & $(0.398)$ \\
Mother tertiary education & $0.267 * * *$ & $0.258 * * *$ & $7.538 * * *$ & $7.338 * * *$ & $4.753 * * *$ & $4.707 * * *$ \\
& $(0.018)$ & $(0.017)$ & $(0.389)$ & $(0.385)$ & $(0.332)$ & $(0.335)$ \\
GDP per capita & $0.001 * * *$ & $0.001 * * *$ & $0.014 * *$ & $0.012 *$ & 0.008 & 0.006 \\
& $(0.000)$ & $(0.000)$ & $(0.007)$ & $(0.007)$ & $(0.005)$ & $(0.006)$ \\
Pre-primary enrollment rate & -0.000 & 0.000 & 0.160 & 0.114 & 0.127 & 0.055 \\
& $(0.005)$ & $(0.005)$ & $(0.204)$ & $(0.204)$ & $(0.138)$ & $(0.157)$ \\
School size & 0.005 & 0.002 & -0.027 & -0.081 & -0.096 & -0.085 \\
School size squared & $(0.003)$ & $(0.002)$ & $(0.086)$ & $(0.086)$ & $(0.076)$ & $(0.079)$ \\
Private primary schools & -0.000 & -0.000 & 0.000 & 0.000 & 0.000 & 0.000 \\
& $(0.000)$ & $(0.000)$ & $(0.000)$ & $(0.000)$ & $(0.000)$ & $(0.000)$ \\
Graduates & $0.001 * *$ & $0.001 * * *$ & 0.014 & 0.010 & 0.007 & -0.000 \\
& $(0.001)$ & $(0.000)$ & $(0.018)$ & $(0.016)$ & $(0.011)$ & $(0.012)$ \\
Employment rate Public Services & -0.015 & -0.012 & 0.456 & 0.076 & $0.550 *$ & 0.004 \\
& $(0.011)$ & $(0.011)$ & $(0.394)$ & $(0.394)$ & $(0.307)$ & $(0.357)$ \\
Employment rate Health-Social Services & 0.014 & 0.015 & $-1.090 *$ & -0.546 & $-1.118 * *$ & -0.655 \\
& $(0.016)$ & $(0.016)$ & $(0.616)$ & $(0.663)$ & $(0.553)$ & $(0.651)$ \\
& -0.016 & -0.011 & $-0.995 * *$ & -0.750 & $-0.535 *$ & -0.077 \\
Child\&Family Info Missing & $(0.012)$ & $(0.011)$ & $(0.467)$ & $(0.482)$ & $(0.303)$ & $(0.349)$ \\
\hline Constant & $X$ & $X$ & $X$ & $X$ & $X$ & $X$ \\
\hline N.Clusters & 0.163 & 0.227 & $56.905 * * *$ & $62.103 * * *$ & $54.424 * * *$ & $58.395 * * *$ \\
N.Observations & $(0.384)$ & $(0.343)$ & $(14.769)$ & $(15.134)$ & $(10.128)$ & $(11.427)$ \\
\hline
\end{tabular}

Significance levels: ${ }^{*} p<0.1,{ }^{* *} p<0.05,{ }^{* * *} p<0.01$. Standard errors are clustered at province level and robust for heteroskedasticity in columns (a) and (b). 
Table 4 Estimates from the non-linear model: OLS and GLS specifications.

\begin{tabular}{|c|c|c|c|c|c|c|}
\hline & \multicolumn{2}{|c|}{ (a) Mother's working status } & \multicolumn{2}{|c|}{ (b) Language test score } & \multicolumn{2}{|c|}{ (c) Math test score } \\
\hline & OLS & GLS & OLS & GLS & OLS & GLS \\
\hline Child care coverage & $\begin{array}{l}0.034 * * * \\
(0.007)\end{array}$ & $\begin{array}{l}0.028 * * * \\
(0.006)\end{array}$ & $\begin{array}{l}0.590 * * * \\
(0.174)\end{array}$ & $\begin{array}{l}0.438 * * \\
(0.182)\end{array}$ & $\begin{array}{c}0.145 \\
(0.118)\end{array}$ & $\begin{array}{c}0.169 \\
(0.158)\end{array}$ \\
\hline Child care coverage squared & $\begin{array}{c}\mathrm{d} \quad-0.001 * * * \\
(0.000)\end{array}$ & $\begin{array}{c}-0.001 * * * \\
(0.000)\end{array}$ & $\begin{array}{c}-0.017 * * \\
(0.007)\end{array}$ & $\begin{array}{c}-0.011 \\
(0.008)\end{array}$ & $\begin{array}{c}-0.007 \\
(0.005)\end{array}$ & $\begin{array}{r}-0.008 \\
(0.007)\end{array}$ \\
\hline N.C & 101 & 101 & 101 & 101 & 101 & 101 \\
\hline N.Observations & 25287 & 25287 & 33708 & 33708 & 33708 & 33708 \\
\hline
\end{tabular}

Significance levels: ${ }^{*} p<0.1,{ }^{* *} p<0.05,{ }^{* * *} p<0.01$. Standard errors are clustered at province level and robust for heteroskedasticity in column (a).

Table 5 Robustness check 1. OLS with province fixed effects and Mundlak-type specification.

\begin{tabular}{|c|c|c|c|c|c|c|}
\hline & \multicolumn{2}{|c|}{ (a) Mother's working status } & \multicolumn{2}{|c|}{ (b) Language test score } & \multicolumn{2}{|c|}{ (c) Math test score } \\
\hline & Prov. FE & Mundlak & Prov. FE & Mundlak & Prov. FE & Mundlak \\
\hline Child care coverage & $\begin{array}{l}0.018 * * * \\
(0.004)\end{array}$ & $\begin{array}{l}0.008 * * * \\
(0.001)\end{array}$ & $\begin{array}{l}0.482 * * * \\
(0.110)\end{array}$ & $\begin{array}{c}0.115 \\
(0.071)\end{array}$ & $\begin{array}{c}-0.071 \\
(0.091)\end{array}$ & $\begin{array}{c}-0.005 \\
(0.065)\end{array}$ \\
\hline Proportion Male & & $\begin{array}{c}0.398 \\
(0.267)\end{array}$ & & $\begin{array}{c}-21.679 * * \\
(10.598)\end{array}$ & & $\begin{array}{c}-19.113 * * \\
(7.756)\end{array}$ \\
\hline Prop Mothers Tertiary Edu & & $\begin{array}{l}0.674 * * \\
(0.279)\end{array}$ & & $\begin{array}{l}31.120 * * \\
(14.299)\end{array}$ & & $\begin{array}{l}16.733 \\
(11.139)\end{array}$ \\
\hline Prop Fathers tertiary Edu & & $\begin{array}{c}-0.407 \\
(0.287)\end{array}$ & & $\begin{array}{l}-23.734 \\
(15.901)\end{array}$ & & $\begin{array}{c}-19.937 * \\
(11.624)\end{array}$ \\
\hline Prop Immigrants & & $\begin{array}{l}1.298 * * * \\
(0.160)\end{array}$ & & $\begin{array}{l}16.675 * * \\
(7.926)\end{array}$ & & $\begin{array}{c}1.140 \\
(7.511)\end{array}$ \\
\hline Prop Individual Missing Values & & $\begin{array}{c}0.214 * \\
(0.122)\end{array}$ & & $\begin{array}{c}-8.813 \\
(6.556)\end{array}$ & & $\begin{array}{c}-5.992 \\
(4.447)\end{array}$ \\
\hline Prop Family Missing Values & & & & $\begin{array}{l}7.530 * * \\
(2.946)\end{array}$ & & $\begin{array}{c}3.860 \\
(3.301)\end{array}$ \\
\hline Individual controls & $X$ & $X$ & $X$ & $X$ & $X$ & $X$ \\
\hline Provincial controls & $X$ & $X$ & $X$ & $X$ & $X$ & $X$ \\
\hline N. Observations & 25287 & 25287 & 33708 & 33708 & 33708 & 33708 \\
\hline $\begin{array}{l}\text { F-test Mundlak spec. } \\
\text { p-value }\end{array}$ & & $\begin{array}{l}81.50 \\
0.0000\end{array}$ & & $\begin{array}{l}18.68 \\
0.0047\end{array}$ & & $\begin{array}{l}10.56 \\
0.1030\end{array}$ \\
\hline
\end{tabular}

Notes. Significance levels: ${ }^{*} p<0.1,{ }^{* *} p<0.05,{ }^{* * *} p<0.01$. Individual and provincial controls: male, non-Italian, father tertiary education and mother tertiary education, GDP, pre-primary enrollment rate, school size and its square, private primary schools, percentage of graduates, employment rate in public services and employment rate in health-social services, dummies for having child or family information missing. Proportion Male, Prop Mothers Tertiary Edu, Prop Fathers tertiary Edu, Prop Immigrants, Prop Individual Missing Values, Prop Family Missing Values represent provincial averages of individual characteristics. The F-test in the Mundlak specification tests the null hypothesis that the coefficients of the provincial averages of individual characteristics are jointly equal to 0 . 
Table 6 Robustness check 2. Missing data, sample heterogeneity and time mismatch.

\begin{tabular}{|c|c|c|c|c|c|c|}
\hline & \multicolumn{2}{|c|}{ (a) Mother's working status } & \multicolumn{2}{|c|}{ (b) Language test score } & \multicolumn{2}{|c|}{ (c) Math test score } \\
\hline & OLS & GLS & OLS & GLS & OLS & GLS \\
\hline \multicolumn{7}{|c|}{ Panel (a): Sample without observations with family info missing } \\
\hline Child care coverage & $\begin{array}{l}0.015 * * * \\
(0.002)\end{array}$ & $\begin{array}{l}0.013 * * * \\
(0.002)\end{array}$ & $\begin{array}{l}0.206 * * * \\
(0.061)\end{array}$ & $\begin{array}{l}0.177 * * * \\
(0.059)\end{array}$ & $\begin{array}{c}-0.046 \\
(0.051)\end{array}$ & $\begin{array}{c}-0.040 \\
(0.065)\end{array}$ \\
\hline N.Observations & 25287 & 25287 & 25287 & 25287 & 25287 & 25287 \\
\hline \multicolumn{7}{|c|}{ Panel (b): Sample without provinces with child care coverage lower than 10th percentile } \\
\hline Child care coverage & $\begin{array}{l}0.012 * * * \\
(0.002)\end{array}$ & $\begin{array}{l}0.011 * * * \\
(0.002)\end{array}$ & $\begin{array}{l}0.172 * * * \\
(0.053)\end{array}$ & $\begin{array}{l}0.169 * * \\
(0.069)\end{array}$ & $\begin{array}{c}-0.006 \\
(0.047)\end{array}$ & $\begin{array}{c}0.013 \\
(0.063)\end{array}$ \\
\hline N.Observations & 22141 & 22141 & 29723 & 29723 & 29723 & 29723 \\
\hline \multicolumn{7}{|c|}{ Panel (c): Sample without provinces with child care coverage higher than 90th percentile } \\
\hline Child care coverage & $\begin{array}{l}0.019 * * * \\
(0.003)\end{array}$ & $\begin{array}{l}0.016 * * * \\
(0.003) \\
\end{array}$ & $\begin{array}{l}0.337 * * * \\
(0.089) \\
\end{array}$ & $\begin{array}{l}0.246 * * * \\
(0.094) \\
\end{array}$ & $\begin{array}{c}0.086 \\
(0.056) \\
\end{array}$ & $\begin{array}{c}0.086 \\
(0.070) \\
\end{array}$ \\
\hline N.Observations & 22961 & 22961 & 30593 & 30593 & 30593 & 30593 \\
\hline \multicolumn{7}{|c|}{ Panel (d): Sample of regular students } \\
\hline Child care coverage & $\begin{array}{l}0.016 * * * \\
(0.002) \\
\end{array}$ & $\begin{array}{l}0.014 * * * \\
(0.002) \\
\end{array}$ & $\begin{array}{l}0.232 * * * \\
(0.062) \\
\end{array}$ & $\begin{array}{l}0.193 * * * \\
(0.069) \\
\end{array}$ & $\begin{array}{c}-0.014 \\
(0.043) \\
\end{array}$ & $\begin{array}{c}-0.002 \\
(0.055) \\
\end{array}$ \\
\hline N.Observations & 24001 & 24001 & 31953 & 31953 & 31953 & 31953 \\
\hline \multicolumn{7}{|c|}{ Panel (e): Estimates using INVALSI 2008-09 data } \\
\hline Child care coverage & $\begin{array}{l}0.011 * * * \\
(0.002) \\
\end{array}$ & $\begin{array}{l}0.010 * * * \\
(0.002) \\
\end{array}$ & $\begin{array}{l}0.090 * * \\
(0.041) \\
\end{array}$ & $\begin{array}{c}0.119 * * \\
(0.051) \\
\end{array}$ & $\begin{array}{c}-0.039 \\
(0.059) \\
\end{array}$ & $\begin{array}{c}-0.001 \\
(0.053) \\
\end{array}$ \\
\hline N.Observations & 27673 & 27673 & 43073 & 43073 & 43073 & 43073 \\
\hline
\end{tabular}

Notes. Significance levels: ${ }^{*} p<0.1,{ }^{* *} p<0.05,{ }^{* * *} p<0.01$. Standard errors are clustered at province level and robust for heteroskedasticity in columns (a) and (b). Controls: male, non-Italian, father tertiary education and mother tertiary education, GDP, pre-primary enrollment rate, school size and its square, private primary schools, percentage of graduates, employment rate in public services and employment rate in health-social services, dummies for having child or family information missing. The 10th percentile of the child care coverage distribution corresponds to 1.16 percent, while the 90 th percentile corresponds to 16 percent. Regular students are those regular in their school path. 